\title{
Exploring Opportunities in Risks of Residential Construction Projects
}

\author{
Djoen San Santoso ${ }^{\mathrm{a}, *}$, Venkata S. Raju Nadimpalli ${ }^{\mathrm{a}}$ \\ ${ }^{a}$ Dept. of Civil and Infrastructure Engineering, School of Engineering and Technology, Asian Institute of Technology, 58 Moo 9, Km. 42, \\ Paholyothin Highway, Klong Luang, Pathumthani 12120, Thailand
}

\begin{abstract}
Construction industry is known for its high risks due to its complexity and vulnerability to external conditions, such as political, weather, etc., as well as project related risk factors. Even though risks may have positive or negative effects, risks have been traditionally viewed as negative aspects that should be minimized or avoided. Thus, opportunities that are actually exist and can be explored in some risks are overlooked. The current risk management process need to be made more robust and efficient to capture the possible ways of exploiting available opportunities in the risks.

This research examined risk factors associated with residential projects in Andhra Pradesh and Telangana states of India from which opportunities can be extracted and further analyzed to identify the risk (opportunity) factors that have high impact on maximizing project value, so that the current risk and opportunity management processes can be made more robust and efficient.

Questionnaire survey was conducted to assess the perceptions of project managers or chief engineers of contractor firms on the risk factors that can be transformed into opportunities in the project execution. From the result, it is found out that even though risks are considered holistically, and the perceived importance is high, the actual implementation is not effective because of the traditional threat-oriented view of the risks. In general, the probability of risks in generating opportunity is not considered to be high. However, a few risk factors could generate high benefit to the project. Eleven important opportunity factors out of 40 factors were identified based on the scores of likelihood and impact. These 11 factors were explored in depth by interviewing experts to gain understanding on the influencing aspects that enable the generation of opportunities from the risk factors and the possible benefits of each opportunity factor.
\end{abstract}

(C) 2018 The Authors. Published by Diamond Congress Ltd., Budapest University of Technology and Economics Peer-review under responsibility of the scientific committee of the Creative Construction Conference 2018.

Keywords: Contractor; India; opportunity; project success; risk.

\section{Introduction}

Construction projects are always associated with risks due to their complexity and dynamic nature. Efficient management of risks is crucial to successfully complete a project within the project objectives of time, cost and quality. Risk management generally deals with identification of risks, assessing their impacts, and developing strategies to create smooth path to achieve project success by mitigating possible risks. However, risks are also connected with opportunities that may have the capability to improve the project value [1,2]. The concept of opportunity management in analysing risk gradually gains acceptance from practitioners and professionals with Project Management Institute (PMI) [3] defines a project risk considering its positive or negative effect on the project objective.

The opportunity aspects of risk may provide additional encouragement for practitioners to apply proper risk management as now the focus is not only on managing the negative effects but also on finding ways to see opportunities on the risk that the project is facing. This opportunity management should be integrated in the risk management process to provide overall view of risks in the project. 
The lack of clear understanding that risk can have positive and negative aspects in the traditional project management leads to misperceptions and thus consequently allows to forgone value opportunity in the project execution. Even though several risk management processes include opportunity in their definition, it is not being implemented by several practitioners because of their threat-oriented view towards risk from a long time [4]. With the above explanation, this research aims to identify and examine risk factors that have association with opportunity in the residential building projects in India.

\section{Risk, uncertainty and opportunity}

As risk typically links to threats, the positive aspects of risk have not been fully explored or even provoked strong debate among risk practitioners and received strong rejections from some individuals and groups [4]. However, with PMI [3] defines risk "an uncertain event or condition that, if it occurs, has a positive or negative effect on one or more project objectives such as scope, schedule, cost, and quality," it provides strong justification to consider the opportunity aspects in the occurrence of risk in the project. With this understanding, risk is not always about threats but also includes opportunities. In line with this, Hillson [4] proposed that by extending the risk process to manage opportunities by process modification, project value maximization can be achieved by exploiting uncertainties to derive opportunities that could remarkably improve project value.

Because of the opportunity aspect that becomes a controversy in the concept of risk, the definition of risk also varies. Standard dictionaries tend to define risk only from the negative side or downside, without considering the upside [4]. The opportunity aspect also defines how risk and uncertainty are considered. When risk is only on the negative side, uncertainty covers both risk and opportunity [4]. On the other hand, there is also another perspective where uncertainty is defined as the probability that the project objectives cannot be reached. In this case, risk is the umbrella of both loss and gain [4].

Olsson [5] argued that most of the existing processes of risk management are not fully capable to manage opportunities in all phases of the project life cycle. In dealing with this, a holistic view must be developed first (as also proposed by Ward and Chapman [6]), followed by the approach to manage opportunities. Meanwhile, Hillson [7] in his study identified many advantages of including opportunity management in the risk process, such as the increase of efficiency by doing two things in one and consequently, no additional overhead in the process is needed. The process also motivated team and supported innovation and creativity in creating benefit, value and saving for the company.

Typically, there are two components of risk that need to be taken into account when analyzing risk, the probability of occurrence of the risk or the frequency of occurrence and the impact of the risk to the project objectives. A risk may have one or more sources and if it occurs, it may have one or more impacts to the project [3]. In the context of risk management, it is common to have some terminologies such as risk source, risk event and risk consequence in analyzing risks. A risk source is something that has potential to give rise to risk. It is from where a risk is originated. Many studies have explored risk sources in international construction projects [8,9,10]. Risk event is defined as an event that occurs such that the source of risk produces consequences. Therefore, a risk event should have a cause and may have consequences. Events without consequences are often referred to as near misses or close calls [11]. The consequence of the risk event that have impact on at least one of the project objectives is defined as the risk consequence. One single risk event may be capable of generating multiple consequences, which can have a positive or negative impact on the project [11].

\section{Research methodology}

This research is based on concept of exploring opportunities in the risks that occur in construction projects with understanding that risks have both negative and positive aspects. The focus of the research is on the residential building projects in India. Both quantitative and qualitative approaches were applied to achieve the objectives of this research.

From literature review, a total of 42 risk factors that have possibility of generating opportunities was extracted and compiled for the purpose of this research. Expert justification was conducted to verify this list of risk factors in terms of their capability of generating opportunity and suitability to the context of residential projects. Severn experts consist of two academicians with 10 years tract record and interest in risk management, and five professional at managerial level with 15 years of experience were consulted for the justification. The justification removed two risk factors from the list. Therefore, in total, there are 40 risk factors used for this research as shown in Table 1. 
After the list of risk factors was justified, they were compiled to be the final questionnaire, which consists of three sections. The first section contains questions regarding the general information of the respondents such as the age, current position, experience, number of projects involved, etc. The second section consists of questions regarding the knowledge and perception of risk and opportunity management. The last section requesting respondents to evaluate the opportunity generated by the risk factors in terms of the likelihood the risk factors generating opportunity and the magnitude of the impact of the opportunity to the project. In the assessments of these two perspectives, five-point Likert scales were employed. The scale for likelihood is 1: never, 2: rarely, 3: sometimes, 4: most likely, and 5: always. The scale for impact is 1: negligible, 2: minor, 3: medium, 4: high, and 5: very high. The impacts of the risk factors to the project objectives of time, cost, and quality were also inquired in this research. Respondents were requested to indicate in which objectives the opportunity can be generated by giving a check. However, the results and findings of this part are not discussed in the paper due to limitation in the scope.

The questionnaire survey was conducted to engineers of contractor firms in Andhra Pradesh and Telangana states of India. In obtaining reliable result for the research, engineers qualified for the survey should have minimum of five years of experience in construction sector. A total of 93 questionnaires was distributed to project managers, assistant project managers, chief engineers, and planning engineers of 46 companies. Most of the questionnaires were distributed face to face to provide opportunity to clearly explain the content of the questionnaire. A few of the questionnaires were sent by email or mail after firstly contacting and explaining the research to the targeted respondents. Some of the questionnaires were collected directly by the survey administrators. Respondents who could not finish the questionnaire at the time of survey and who received the questionnaire by mail were provided with return envelope with address and stamp on it.

Data collected from the survey was analysed to generate ranks of likelihood and impact by considering the mean values of the risk factors. These mean values were plotted to the graph to identify important risk factors in generating opportunity. A threshold of mean value of 3.0 for both likelihood and impact is used in identifying the important risk factors. Semi-structured interviews with experts were conducted to understand how the risk factors generating opportunities. Factors that influencing the generation of opportunity from the risk factors and opportunities that can be generated were the two main aspects the interviews tried to explore. The focus was on the important opportunity risk factors, which were identified based on the likelihood and impact. Five senior project managers with more than 15 years of experience in construction projects were requested for this purpose. Each interview took around one and a half hour to two hours.

\section{Results and discussion}

A total of 57 valid questionnaires from 33 companies were collected from the survey, representing $61 \%$ response rate. To check reliability of the collected data, Cronbach's Alpha test was applied and yielded a value of 0.912 , which implies an excellent reliability. The mean values and ranks of the risk factors from the perspective of likelihood and impact are tabulated in Tables 1 and 2.

Table 1 shows that the highest mean value is 3.7 for risk factor related to the change in construction method or technology and there are only 13 risk factors, out of 40 factors, that have mean values higher than 3.0. This implies that only less than half of the risk factors have likelihood of generating positive consequences to the project with medium probability of occurrence. Many of the risk factors have less probability to be converted to be opportunity for the project benefits.

In terms of the impact of the opportunity that can be generated by the risk factors (Table 2), in general, the evaluation was slightly higher than the likelihood with three risk factors obtained mean value higher than 4.0, indicating high opportunity impact to the project. The three risk factors are political preference toward the project, construction method or technology, and top management support of the contractor. Twenty-seven risk factors can generate medium to high impact on the level of opportunity generated. Only a few of the risk factors have minor impact with inflation (mean=1.88) has the lowest degree of generating positive impact. This indicated that in general respondents considered that the opportunities in the risk factors are worth to be explored.

Many research studies have assessed the important of risk factors by considering both the degree of impact and likelihood or frequency of occurrence. This same principle was used to identify the important risk factors in generating positive aspects to the project. The likelihood and degree of positive impact of the risk factors were plotted to the graph to produce likelihood-impact matrix as shown in Fig. 1. The important opportunity risk factors were identified by those having mean values of both likelihood and impact not less than 3.0. From a total of 40 risk factors, eleven risk factors are identified as important opportunity risk factors as listed below: 
Table 1. Mean values and rank of risk factors from likelihood perspective

\begin{tabular}{|c|c|c|c|}
\hline Factor & Mean & Std. Dev. & Rank \\
\hline Change in construction methods or technology [F11] & 3.74 & 0.44 & 1 \\
\hline Change in design [F12] & 3.47 & 0.66 & 2 \\
\hline Change in interest rates $[\mathrm{F} 4]$ & 3.46 & 0.71 & 3 \\
\hline Change in performance of workers [F26] & 3.25 & 0.87 & 4 \\
\hline Change in top management support of the contractor [F27] & 3.23 & 0.46 & 5 \\
\hline Change in expectations or objectives of the project [F18] & 3.21 & 0.84 & 6 \\
\hline Change in schedule by the owner [F24] & 3.19 & 0.55 & 7 \\
\hline Change in tax rates [F3] & 3.16 & 0.53 & 8 \\
\hline Change in project organization structure [F28] & 3.11 & 0.79 & 9 \\
\hline Change in political preference towards the project [F7] & 3.11 & 0.75 & 10 \\
\hline Change in government's policy related to the project [F5] & 3.07 & 0.70 & 11 \\
\hline Fluctuation in currency rates [F2] & 3.04 & 0.76 & 12 \\
\hline Change in scope of work [F19] & 3.02 & 0.77 & 13 \\
\hline Change in availability of equipment [F37] & 2.98 & 0.72 & 14 \\
\hline Change in project size [F14] & 2.98 & 0.69 & 15 \\
\hline Change in regulations and laws related to the project [F8] & 2.97 & 0.63 & 16 \\
\hline Change in performance of nominated subcontractor [F22] & 2.95 & 0.69 & 17 \\
\hline Change in availability of supplier [F34] & 2.81 & 0.52 & 18 \\
\hline $\begin{array}{l}\text { Change in coordination between subcontractor and nominated } \\
\text { subcontractor [F23] }\end{array}$ & 2.79 & 0.49 & 19 \\
\hline Change in availability of material [F35] & 2.75 & 0.83 & 20 \\
\hline Change in codes and standards [F9] & 2.74 & 0.44 & 21 \\
\hline Different geological conditions [F30] & 2.72 & 1.11 & 22 \\
\hline Change in government's attitude towards foreign investors [F6] & 2.70 & 0.46 & 23 \\
\hline Change in project milestones [F20] & 2.70 & 0.80 & 24 \\
\hline Change in availability of labour [F36] & 2.65 & 0.48 & 25 \\
\hline Change in contractual relations [F10] & 2.61 & 0.77 & 26 \\
\hline Different site conditions [F31] & 2.60 & 0.50 & 27 \\
\hline Unexpected breakdown of machinery [F38] & 2.58 & 0.53 & 28 \\
\hline Different cost estimation [F29] & 2.56 & 0.57 & 29 \\
\hline Damage to site due to natural disasters [F39] & 2.53 & 0.50 & 30 \\
\hline Change in public relations of the contractor [F32] & 2.51 & 0.50 & 31 \\
\hline Change in staff of owner [F17] & 2.51 & 0.50 & 32 \\
\hline Change in material $[\mathrm{F} 13]$ & 2.49 & 0.50 & 33 \\
\hline $\begin{array}{l}\text { Change in roles and responsibilities of the contractor and nominated } \\
\text { subcontractor [F21] }\end{array}$ & 2.47 & 0.89 & 34 \\
\hline Change in inflation [F1] & 2.39 & 0.67 & 35 \\
\hline Change in financial conditions of the owner [F16] & 2.25 & 0.43 & 36 \\
\hline Change in international relations of the contractor [F33] & 2.25 & 0.43 & 37 \\
\hline Change in financial conditions of contractor [F25] & 2.25 & 0.83 & 38 \\
\hline Historical findings [F40] & 2.14 & 0.88 & 39 \\
\hline Different weather conditions [F29] & 2.00 & 0.71 & 40 \\
\hline
\end{tabular}


Table 2. Mean values and rank of risk factors from degree of impact perspective

\begin{tabular}{|c|c|c|c|}
\hline Factor & Mean & Std. Dev. & Rank \\
\hline Change in political preference towards the project [F7] & 4.35 & 0.64 & 1 \\
\hline Change in construction methods or technology [F11] & 4.25 & 0.43 & 2 \\
\hline Change in top management support of the contractor [F27] & 4.23 & 0.82 & 3 \\
\hline Change in government's policy related to the project [F5] & 3.72 & 0.45 & 4 \\
\hline Change in project organization structure [F28] & 3.70 & 0.73 & 5 \\
\hline Change in financial conditions of the owner [F16] & 3.68 & 0.51 & 6 \\
\hline Change in availability of supplier [F37] & 3.67 & 0.51 & 7 \\
\hline Change in design [F12] & 3.63 & 0.56 & 8 \\
\hline Change in availability of labour [F36] & 3.61 & 0.56 & 9 \\
\hline Change in scope of work [F19] & 3.60 & 0.53 & 10 \\
\hline Change in performance of nominated subcontractor [F22] & 3.58 & 1.03 & 11 \\
\hline Change in expectations or objectives of the project [F18] & 3.56 & 0.54 & 12 \\
\hline Change in performance of workers [F26] & 3.54 & 0.54 & 13 \\
\hline Change in availability of equipment [F37] & 3.53 & 0.54 & 14 \\
\hline Change in contractual relations [F10] & 3.51 & 0.50 & 15 \\
\hline Different site conditions [F31] & 3.49 & 0.50 & 16 \\
\hline Change in availability of material [F35] & 3.47 & 1.09 & 17 \\
\hline Change in financial conditions of contractor [F25] & 3.26 & 1.30 & 18 \\
\hline Change in project size $[\mathrm{F} 14]$ & 3.25 & 0.43 & 19 \\
\hline Different cost estimation [F15] & 3.25 & 0.43 & 20 \\
\hline Change in material [F13] & 3.23 & 0.46 & 21 \\
\hline Change in project milestones [F20] & 3.21 & 0.84 & 22 \\
\hline Damage to site due to natural disasters [F39] & 3.21 & 0.67 & 23 \\
\hline Change in regulations and laws related to the project [F8] & 3.18 & 0.50 & 24 \\
\hline Unexpected breakdown of machinery [F38] & 3.16 & 0.53 & 25 \\
\hline Change in interest rates $[\mathrm{F} 4]$ & 3.11 & 0.52 & 26 \\
\hline Change in schedule by the owner [F24] & 3.09 & 0.61 & 27 \\
\hline Change in public relations of the contractor [F32] & 3.07 & 0.42 & 28 \\
\hline $\begin{array}{l}\text { Change in coordination between subcontractor and nominated } \\
\text { subcontractor [F23] }\end{array}$ & 3.05 & 0.79 & 29 \\
\hline Change in codes and standards [F9] & 3.04 & 0.71 & 30 \\
\hline Different geological conditions [F30] & 2.97 & 1.25 & 31 \\
\hline Different weather conditions [F29] & 2.84 & 1.26 & 32 \\
\hline Change in staff of owner [F17] & 2.77 & 0.85 & 33 \\
\hline Change in government's attitude towards foreign investors [F6] & 2.77 & 0.85 & 34 \\
\hline Change in tax rates $[\mathrm{F} 3]$ & 2.51 & 0.50 & 35 \\
\hline Change in international relations of the contractor [F33] & 2.49 & 0.50 & 36 \\
\hline Historical findings [F40] & 2.25 & 0.79 & 37 \\
\hline $\begin{array}{l}\text { Change in roles and responsibilities of the contractor and nominated } \\
\text { subcontractor [F21] }\end{array}$ & 2.23 & 1.10 & 38 \\
\hline Fluctuation in currency rates [F2] & 2.21 & 0.49 & 39 \\
\hline Change in inflation [F1] & 1.88 & 0.54 & 40 \\
\hline
\end{tabular}




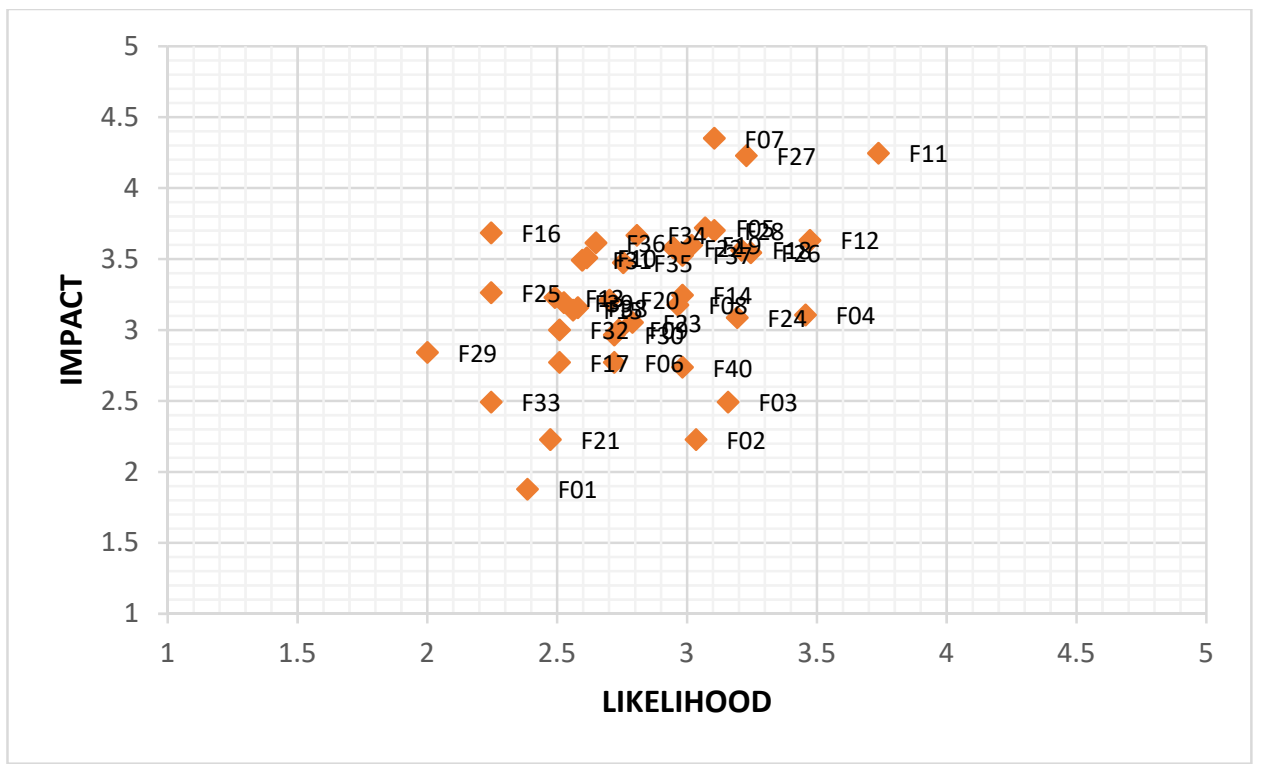

Fig. 1. Likelihood impact matrix.

1. Change in construction methods or technology [F11]

2. Change in top management support of the contractor [F27]

3. Change in political preference towards the project [F07]

4. Change in design [F12]

5. Change in performance of workers [F26]

6. Change in project organization structure [F28]

7. Change in expectations or objectives of the project [F18]

8. Change in government's policy related to the project [F05]

9. Change in scope of work [F19]

10. Change in interest rates [F04]

11. Change in schedule by the owner [F24]

Due to the limitation of space, the results of the interviews are presented only for the first two important opportunity risk factors, i.e. change in construction methods or technology [F11] and change in top management support of the contractor [F27]. They are discussed in the following subsections.

\subsection{Change in construction methods and technology [F11]}

This risk factor is on the first and second ranks for likelihood and impact, respectively. The dynamic environment of construction projects facilitates the development of new construction methods or technology to increase productivity and safety. Contractors need to adapt on and adopt this new development in order to be competitive and to exploit the maximum possible benefits. Even though some of the enterprises deal it as a risk, this factor has the capability to generate opportunity, which helps in achieving the project objectives. In grabbing the opportunity from the factor, various parameters, both internal and external, have to be managed efficiently. Various influencing parameters and the exploitable benefits that can be generated from the factor are displayed in Fig. 2. The I and E symbols after influencing parameters represent the category of the parameter: internal and external, respectively.

Efficient IT knowledge of the contractor is one of the influencing parameters and is crucial in the rapidly upgrading technological environment and it helps in increasing the productivity. Management capability of the contractor is another crucial influencing parameter which is essential to deal with change and increase the productivity. When there is a change in the construction method or technology knowledge of the new method or technology is very crucial in 
order carry out the work smoothly without any accidents and to have superior control over the quality of work. Experience of the technical personnel who are involved in the project is another crucial parameter which helps in completing the project as per schedule or even before the schedule despite of the new method or technology. Adequacy of the availability of the plant and labour resources is also an important influencing parameter which helps in completion of the project earlier that the expected schedule.

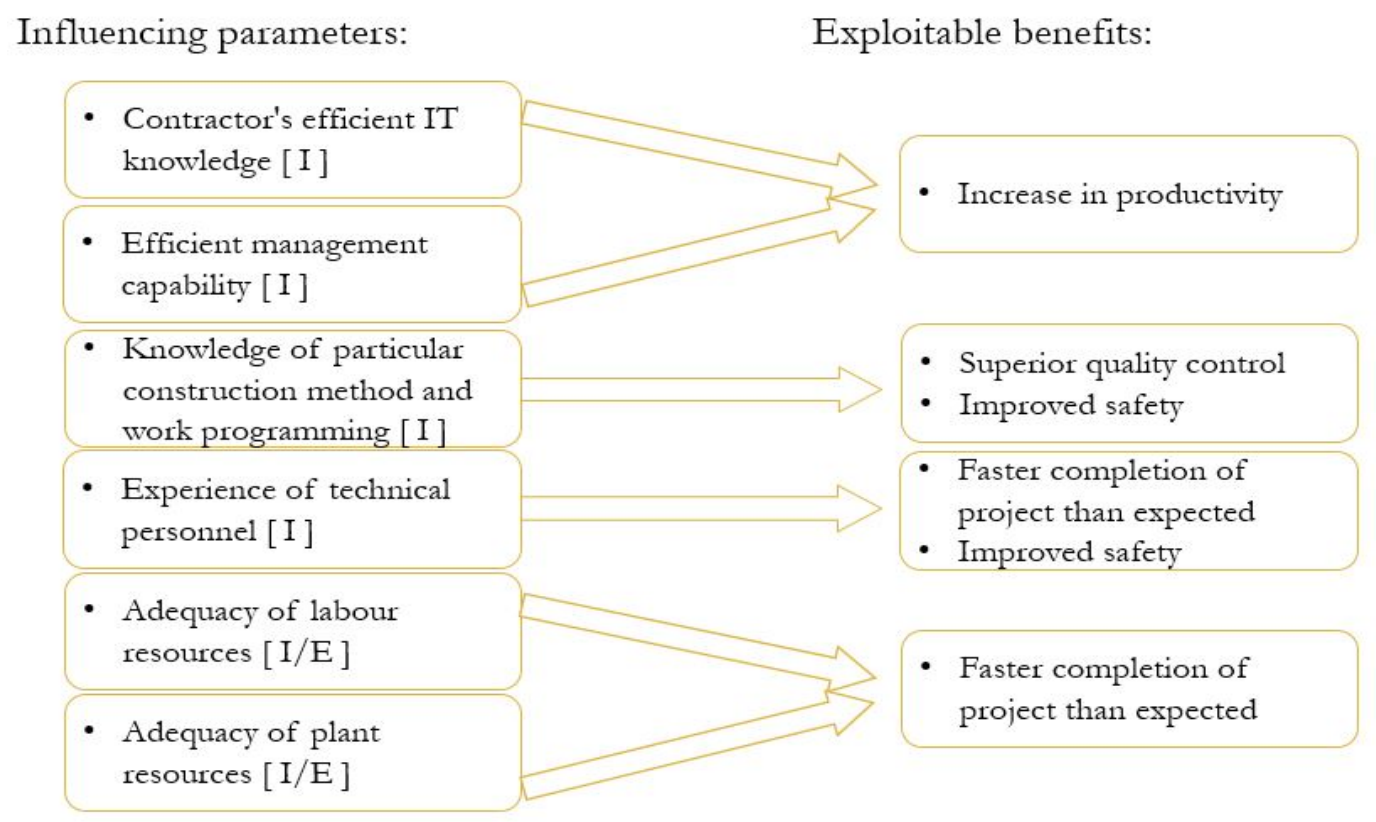

Fig. 2. Diagram explaining the influence parameters and benefits of change in construction methods and technology.

\subsection{Change in top management support of the contractor [F27]}

Change in top management support of the contractor is on the fifth rank in term of likelihood, but it ranks third in the degree of impact. Commitment of top management has always been found to be one of the most important factors contributing to project success by many studies. The same applies to the opportunity management in dealing with risks as long as a solid and systematic organization structure has been well developed in the company and fully integrated to the projects. This risk factor can generate positive aspects when more supports are provided from the top management to the project or when head office decentralizes some authorities to the project site. The later part can be viewed as a less support provided to the project site (risk/negative aspect) if no proper system or procedure is established on the authorities allocated to the project and no proper communication on the allocation to the project personnel.

As this factor deals directly within the contractor's company, all influence parameters are internal parameters as depicted in Fig. 3. One of the influencing parameters is organizational structure. A supportive project organizational structure is helpful in increasing the productivity, smooth flow of the project with minimum possible threats, and generating healthy and positive relationship among the project staff. Interactive inter departmental groups in the project is another parameter that facilitates free flow of communication among the various departments in the projects and can certainly generate benefits.

Quality is one of the crucial variables in achieving the success of project and the quality management plan is not a responsibility of one department or individual thus organizational quality project plan is an important influencing parameter to make sure that each project can achieve the required quality. Proper decision-making process is always important and to exploit it, project management office (PMO), whenever it is available, should be included in the process to develop solid project procedure in monitoring and evaluating the progress to gain control over budget, schedule, and quality of the works so project execution can be done smoothly and efficiently within the project. 
Influencing parameters:

\begin{tabular}{|c|c|}
\hline $\begin{array}{l}\text { - Supportive project } \\
\text { organizational structure [I] }\end{array}$ & $\begin{array}{l}\text { - Increase in productivity } \\
\text { - Healthy relationship between the project } \\
\text { staff }\end{array}$ \\
\hline - Existence of interactive inter- & - Reduced threats and smooth flow of project \\
\hline departmental project groups [I] & - Increase in productivity \\
\hline - Efficiency of organizational & $\begin{array}{l}\text { Healthy relationship between the project } \\
\text { staff }\end{array}$ \\
\hline [I] & - Reduced reworks \\
\hline $\begin{array}{l}\text { - PMO involvement in decision } \\
\text { making [I] }\end{array}$ & $\begin{array}{l}\text { - Increase in productivity } \\
\text { - Reduced threats and smooth flow of project }\end{array}$ \\
\hline $\begin{array}{l}\text { - Use of standard project tools } \\
\text { and techniques to review and } \\
\text { assess the progress of work [I] }\end{array}$ & $\begin{array}{l}\text { - Timely delivery of the project } \\
\text { - Reduced threats and smooth flow of project } \\
\text { - Reduced reworks }\end{array}$ \\
\hline $\begin{array}{l}\text { - Existence of project procedures } \\
\text { [I] }\end{array}$ & $\begin{array}{l}\text { - Timely delivery of the project } \\
\text { - Reduced threats and smooth flow of project } \\
\text { - Superior quality control }\end{array}$ \\
\hline
\end{tabular}

Fig. 3. Diagram explaining the influence parameters and benefits of change in top management support.

\section{Conclusions}

The study of opportunity in risks of residential projects in India indicated that opportunity was perceived in some risk factors but, in general, the likelihood was considered not so high. Although the probability was not high, a few of them were assessed to be able to contribute positive aspects to the project success. Eleven important opportunity risk factors were extracted based on their likelihood and impact to the project, which cover aspects related to construction methods or technology, top management support of the contractor, political preference towards the project, design, performance of workers, project organization structure, expectations or objectives of the project, government's policy related to the project, scope of work, interest rates, and schedule of project from owner. Influencing parameters and exploitable benefits were explored and explained for each of these important opportunity risk factors based on the interviews of five experts. Diagrams summarizing the interview results were developed to help practitioners adopt, optimize, and improve opportunity management in dealing with risks.

\section{References}

[1] Jaafari, A. (2007). Project and program diagnostics: a systemic approach. International Journal of Project Management, 25, 781-790.

[2] Al-Bahar, J., \& Crandall, K. (1990). Systematic Risk Management Approach for Construction Projects. Journal of Construction Management. $116(3), 533-546$.

[3] PMI. (2000). A guide to the project management body of knowledge (PMBOK guide). Project Management Institue, Newtown Square.

[4] Hillson, D. (2002). "Extending the risk process to manage opportunities". International Journal of Project Management, 20(3), 235-240.

[5] Olsson, R. (2007). In search of opportunity management: Is the risk management process enough? International Journal of Project Management, 25, $745-752$.

[6] Ward, S., \& Chapman, C. (2003). Transforming project risk management into project uncertainty management. International Journal of Project Management, 21(2), 97-105.

[7] Hillson, D. (2005). Effective Opportunity Management for Projects: Exploiting Positive Risk. Marcel Dekker, Inc., New York.

[8] Han, S. H., Park, S. H., Kim, D. Y., Kim, H., \& Kang, Y. W. (2007). Causes of Bad Profit in Overseas Construction Projects. Journal of Construction Engineering and Management, 133(12), 932-943.

[9] Han, S.H., and Diekmann, J.E. (2001). "Approaches for making risk-based go/no-go decision for international projects", Journal of Construction Engineering and Management, 127(4), 300-308.

[10] Zhi, H. (1995). Risk management for overseas construction projects. International Journal of Project Management, 13(4), $231-237$.

[11] Fidan, G. (2008). A risk and vulnerability ontology for construction projects. Doctoral dissertation. Middle East Technical University, Ankara, Turkey. 